\title{
Тувинская рукопись «Сутры о восьми светоносных» как книжный талисман
}

\author{
Саглара В. Мирзаева
}

Калмыцкий научный цеентр Российской академии наук, Российская Федерация

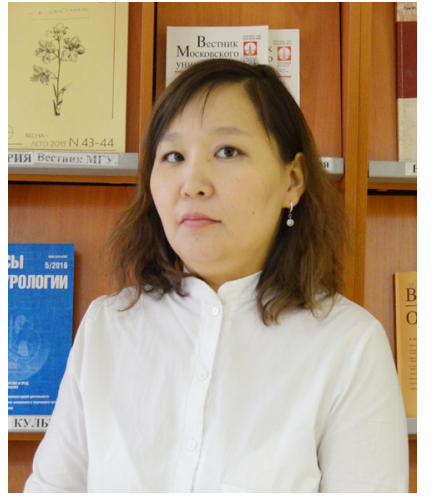

транслитерация текста.

В статье вводится в научный оборот текст монголоязычной рукописи «Naiman gegen neretü јии tarni» ('Талисман-тарни «Восьми светоносных»') из рукописного фонда Национального музея Республики Тыва (М-828). Он содержит ценные материалы по традиции бытования талисманов буу / бу в тибето-монгольском буддизме.

В данном сочинении, другая версия которого представлена в рукописной коллекции Харбухын Балгас (Булганский аймак, Монголия), содержатся изображения различных талисманов, сопровождаемые сакральными формулами и описанием выполняемых ими функций. Всего в рукописи выявлены тридцать три изображения талисманов, предназначенных для различных цеелей: от семейного благополучия до высшей цели буддийского пути.

Тувинская рукопись носит компилятивный характер. За описанием талисманов, имеющим ритуальное предназначение, следует небольшой нарратив, повествующий об истории создания Буддой Шакьямуни книжного талисмана «Восьми светоносных». В статье приводится описание некоторых талисманов-тарни (bии tarni) согласно тексту рукописи, в приложение в цзелях введения памятника в научный оборот включена

Ключевые слова: «Сутра о восьми светоносных неба и земли»; «Талисман-тарни „Восьми светоносных“»; книжный талисман; талисман буу; тибето-монгольский буддиз; Национальный музей Республики Тыва; Тува

Исследование проведено в рамках государственной субсидии - проект «Устное и письменное наследие монгольских народов России, Монголии и Китая: трансграничные традиции и взаимодействия» (номер госрегистрации: АAAA-A19-119011490036-1).

Для цитирования:

Мирзаева С. В. Тувинская рукопись «Сутры о восьми светоносных» как книжный талисман // Новые исследования Тувы. 2021, № 3. С. 164-177. DOI: https://www.doi.org/10.25178/nit.2021.3.13

Мирзаева Саглара Викторовна - научный сотрудник отдела письменных памятников и языкознания Калмыцкого научного центра РАН. Адрес: 358000, Российская Федерация, г. Элиста, ул. им. И. К. Илишкина, д. 8. Тел.: +7 (84722) 3-55-06. Эл. адрес: saglaramirzaeva@kigiran.com

MIRZAEVA, Saglara Viktorovna, Research Associate, Department of Mongolian Languages and Written Sources, Kalmyk Scientific Center, Russian Academy of Sciences. Postal address: 8 Ilishkin St., 358000 Elista, Russian Federation. Tel.: + 7 (84722) 3-55-06. E-mail: saglaramirzaeva@kigiran.com 


\title{
A Tuvan manuscript of the Sutra of Eight Luminous as a Booklore Talisman
}

\author{
Saglara V. Mirzaeva \\ Kalmyk Scientific Center of the Russian Academy of Sciences, Russian Federation
}

\begin{abstract}
The article introduces the text of the Mongolian manuscript «Naiman gegen neretü juu tarni» (Talisman-tarni Called Eight Luminous) kept in the National Museum of the Republic of Tuva (M-828). It contains valuable data on the tradition of buu / bu talismans in Buddhism of Tibet and Mongolia.

This manuscript, another version of which is found in the collection of Harbukhyn Balgas (Bulgan aimag of Mongolia), includes images of various talismans, followed by sacred spells and brief description of their functions. In total, thirty-three images of talismans were identified in the manuscript. All pursue various goals - from family welfare and prosperity to the highest goal of the Buddhist path.

The source manuscript is of a compilative character: the list of the talismans, which, obviously, is ritually intended, is followed by a short narrative telling how this booklore talisman named "The Eight Luminous" was given by Buddha Sakyamuni. Description of some tarni talismans (buu tarni) is given according to the text. The article provides also transliteration of the manuscript.
\end{abstract}

Keywords: The Sutra of the Eight Luminous; tarni talisman of the Eight Luminous; booklore talisman; buu talisman; Buddhism in Tibet and Mongolia; National Museum of the Republic of Tuva; Tuva

\author{
Financing \\ The study was carried out within the framework of state subsidies - the project "Oral and Written Heritage of the Mongolian Peoples
} of Russia, Mongolia and China: Cross-Border Traditions and Interactions" (registration number AAAA-A19-119011490036-1).

For citation:
Mirzaeva S. V. Tuvinskaia rukopis» «Sutry o vos'mi svetonosnykh» kak knizhnyi talisman [A Tuvan manuscript of the
Sutra of Eight Luminous as a Booklore Talisman]. New Research of Tuva, 2021, no. 3, pp. 164-177. (In Russ.). DOI: https://
www.doi.org/10.25178/nit.2021.3.13

\section{Введение}

Буддийские талисманы, или обереги, как часть популярного буддизма народов Центральной Азии, все еще не изучены в полной мере. Одним из таких талисманов является монг. буу / калм. бу (от кит. fu), который описывается исследователями как листок бумаги с написанной на нем сакральной формулой, обернутый тканью или кожей (Житецкий, 1893: 29; Шараева, 2009: 260). Очевидно, что происхождение талисмана буу восходит к даосизму: аналогичные амулеты $f u$ / fu lu (符籙) ‘письменный талисман’ в даосизме, возникновение которого датируют I-II вв. н. э., представляют собой комбинацию текста и некоего символического изображения, выполняющего магическую функцию (Benebell, 2016). Как справедливо отмечает А. Д. Цендина, традиция бытования подобных книжных талисманов, как и многие другие сферы письменной культуры народов Центральной Азии, представляет собой многослойный комплекс, в котором перемешаны индийские, китайские, тибетские и собственно монгольские компоненты (Tsendina, 2020: 1637).

Предметом данной статьи выступает рукопись «Naiman gegen neretü juи tarni» ('Талисман-тарни «Восьми светоносных»') (предположительно, не ранее XVII в.), которая содержит ценный материал 
по талисманам буу / буу тарни. Данный текст относится к кругу версий апокрифической дхаранисутры «Сутра о восьми светоносных неба и земли» китайского происхождения. Некоторые сведения о литературной истории текста этой сутры и ее основных версиях содержатся в публикациях (Срба, 2017; Мирзаева, 2019ab; Мирзаева, Тувшинтугс, 2019, 2020; Мирзаева, 2020ab). Несмотря на сравнительно небольшой объем, она сыграла роль в формировании тибето-монгольской литературы, поскольку, помимо нескольких редакций текста, на ее основе создавались как ритуальные тексты (подношения воскурений-санг), так и повествовательные нарративы, рассказывающие о пользе чтения этой сутры.

Актуальность работы обусловлена в первую очередь тем, что эта версия «Сутры о восьми светоносных неба и земли» прежде не упоминалась в научно-исследовательской литературе. Обнаружение ее в коллекции Национального музея им. Алдан-Маадыр Республики Тыва (далее - НМ РТ), обусловленное тем, что в прошлом эта территория входила в сферу влияния монгольской письменной традиции, свидетельствует о ценности этой коллекции в корпусе буддийской литературы и необходимости ее дальнейшего изучения. Содержащиеся в рукописи сведения по оформлению талисманов буу и выполняемым ими функциям представляют собой уникальный материал по народному буддизму, в котором буддийский канон, переплетаясь с местными реалиями, формирует локальную тувинскую традицию. Изучение аналогичных ритуальных буддийских текстов из фондохранилищ Тувы в сравнении с тибетскими и монгольскими оригиналами позволит в дальнейшем дать подробное описание специфики тувинского буддизма внутри общей тибето-монгольской традиции.

Целью публикации является введение рукописи «Naiman gegen neretü juи tarni» в научный оборот, а также описание традиции бытования талисманов буу в тибето-монгольском буддизме, некоторых их разновидностей и выполняемых ими функций на материале этой рукописи.

\section{Общая характеристика рукописи}

Рукопись «Naiman gegen neretü јии tarni» (М-828) хранится в фонде Национального музея Республики Тыва под инв. № M-828, состоит из 8 листов; титул отсутствует (название на л. 7v: Naiman gegen neretü ји јии tarni); размеры листа 20.5*7.5 см, 18-19 строк на листе (Sazykin, 1994: M-828, 381). Пагинация полистная (nigen, qoyar, $\gamma$ urban и т. д.), проставлена в левой части листа по центру. Текст написан черными чернилами, изображения талисманов выделены красным (на последнем листе 8v - выкрашены в цвет, указанный в описании отдельного талисмана: например, зеленый (монг. noyojan önggetei) (HM PT, M-828, л. 8v: 3-4) и красный (монг. ulaүan) (НM PT, M-828, л. 8v: 10)).

Как было указано выше, рассматриваемая рукопись представляет собой версию буддийской дхарани-сутры «Сутра о восьми светоносных неба и земли», которая не была прежде описана в исследовательской литературе. В качестве исключения можно назвать рукопись XВМ 153 из каталога монгольской коллекции Харбухын Балгас Э. Кьодо, название которой, ввиду плохой сохранности текста, восстановлено составителем как «Joo-tu [na]ran gegen neretü nom nigen jüil-tü sudur» (One Chapter of the book called Sunlight (?) with the joo (?), 'Раздел книги, называемый “Солнечный свет”, с [талисманом]30о') (Chiodo, 2009: 191). Сравнение этого текста с нашим источником показывает, что в их основе лежит один и тот же текст, однако, что касается изображений талисманов, фрагментарность текста ХВМ 153 и отсутствие рисунков в уцелевших фрагментах рукописи ${ }^{1}$ лишают нас возможности сравнить их с рукописью М-828.

Термин јоo 2 Э. Кьодо объясняет как заимствованное кит. zhao и, таким образом, интерпретирует его как «талисман, дарованный небесным ${ }^{3}$ правителем» (там же: 191). Исследовательница указывает, что этот талисман использовался монгольскими скотоводами в защитных ритуалах (там же: 192), а также, как упоминается в некоторых текстах, - для устранения последствий плохих предзнаменований, связанных с животными (там же: 196). В частности, автор упоминает ойратский текст под названием «Temegēni jasal kekü sudur ene bui» ('Сутра, исправляющая [приметы, связанные с] верблюдами') (там же: 196), в котором повторяется лейтмотив batu јоu bičiq ene bui ('это сильный талисман-зоу'),

\footnotetext{
${ }^{1}$ Единственное изображение, обнаруженное в рукописи XВM 153 (Chiodo, 2009: прил. XBM 153, 4v), не соответствует ни одному изображению в М-828.

${ }^{2}$ А. Г. Сазыкин транслитерирует как јuи (Sazykin, 1994: 381). Автор придерживается этого варианта транслитерации.

${ }^{3}$ Как противоположность земному.
} 
присутствующий и в рассматриваемом источнике. В тексте ХВМ 155 из коллекции Харбухын Балгас лексема јоо имеет значение 'изображение, создаваемое для того, чтобы больной выздоровел’ (там же: 192).

Рукопись начинается с трехчастной молитвы Прибежища и шестислоговой мантры Авалокитешвары, после чего следуют изображения талисманов, сопровождаемые санскритскими формулами дхарани (не во всех случаях) и описанием функций каждого талисмана. Интересно отметить, что, несмотря на название текста, с самой «Сутрой о восьми светоносных неба и земли» связана лишь одна формула дхарани к рис. 28 om akani nikani abila mandal-a maq-amali manda-ray-a so hā (HM PT, M-828, л. 5v: 13-16), которую в сутре дарует Будда в ответ на просьбу бодхисаттвы Асанги. Всего в тексте мы находим тридцать три изображения талисманов буу, последний из которых относится к группе sa yig / bza' yig 'надпись; надпись, которую нужно съесть' (Tsendina, 2020: 1636). А. Д. Цендина указывает, что эти талисманы представляют собой комбинации знаков или букв, которые нужно съесть в случае болезни или опасности (там же: 1636). В рукописи «Naiman gegen neretü juи tarni» этот талисман, состоящий из слогов ha / la /ma / la / la / rla, назван талисманом хозяев местности (монг. yajar-un ejed-ün buu) (HМ РТ, M-828, л. 8v: 11).

\section{Транслитерация рукописи}

\begin{tabular}{|c|c|}
\hline \multicolumn{2}{|c|}{ № строки } \\
\hline 1 & [1v] Namo buddi-a:: namo \\
\hline 2 & dharmay-a:: namo sangghay-a:: \\
\hline 3 & om mani bad mi huṃ:: om siri \\
\hline 4 & siri mani \\
\hline 5 & mani hum \\
\hline 6 & hum so hā hum bad \\
\hline 7 & so hā: orongnadu daisun-du \\
\hline 8 & olja oropuluүči oron-a segürgel \\
\hline 9 & sün-dü surulqadu boltayulugči \\
\hline 10 & qutuү-tu batu ju bičig ene bui: \\
\hline 11 & burutan-i bolbasu \\
\hline 12 & 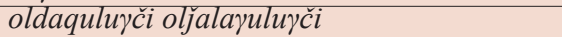 \\
\hline 13 & qutuү-tu ru bičig ene bui: \\
\hline 14 & qan ejen-dür/ \\
\hline 15 & -iyen öljeitü sari daisun/ \\
\hline 16 & -du tariy-a-tu boyda ejen-dür-iyen \\
\hline 17 & öljei-tü buruүu joriy-tu \\
\hline 18 & daisun-dur tariy-a-tu: öber-ün \\
\hline 1 & [2r] ejen-dür-iyen öljei-tü \\
\hline 2 & öber-e dayisun-dur tariy-a-tu \\
\hline$\overline{3}$ & el ulus-dur-iyan öljei-tü: \\
\hline 4 & ergeleldekü dayisun-du tariy-a-tu \\
\hline 5 & qutuү-tu јu batu bičig ene bui: \\
\hline 6 & om sari agavaran-a \\
\hline 7 & sagari čaru qačabo \\
\hline 8 & so hā:: \\
\hline 9 & erketü tngri-yin \\
\hline 10 & jayayan-bar erten/ \\
\hline 11 & -ece orosizsan qutuy-tu blam-a-yin \\
\hline 12 & 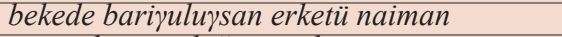 \\
\hline 13 & gegen batu ru bičig ene bui: emi \\
\hline 14 & dom ülü \\
\hline 15 & endegül \\
\hline 16 & 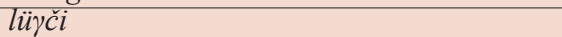 \\
\hline 17 & qutuү-tu batu ju bičig ene \\
\hline 18 & bui: oroi-daki \\
\hline 19 & 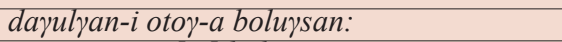 \\
\hline 20 & 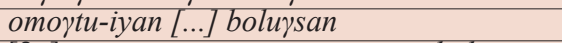 \\
\hline 1 & 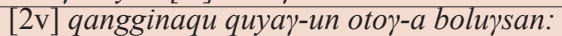 \\
\hline 2 & qataraqu moran-du cimeg boluүsan: \\
\hline 3 & qayiratu qutuүtu batu juu bičig \\
\hline 4 & ene bui:: motai om sovasti bavan/ \\
\hline 5 & tu sarva sadunanča \\
\hline
\end{tabular}




\section{НОВЫЕ ИССЛЕДОВАНИЯ ТУВЫ}

www.nit.tuva.asia

\section{No3}

suun bad so hā: ene tarni juu-yi

ulayan-iyar gerlejü doloyan tariy-al

-u köröngge keju arban jüg-tü

dalalbasu bayan sayin boluyu::

sayurgeri beri suuntu

so hā:: köbegün ese

toytabasu čaran keji-yin üri kejü

jegülgebesü jayayan ügei ber boll

.. busu toytayu.

om sarva saduruni

bakari so hā::

gergetü-tü-yin kümün-i sedkil ese

nayirabasu ber tegün-i oroi-yin

geser-i kejü jegübesü öber-ün

[3r] sedkil-iyer nomoyadqu

bolai: sarim maq-a

so hā::

genüte ebečin kürtebesü ene tarni

buu-yi jegüjü kükü-ber beyeben

utubasu ebečin arilqu bolai:

om ags-a daru

hum bad so hä:: busud-luy-a

yaraqu temečen unnabasu ene tarni

buu-yi jigürtü uuli-yi

arisun-dur kejü ebüdüg-dür

qandu-ču sögüdün savubasu

öber-iyen boluyu:: om sari

sari ana kari so

hā:: egüni dotur-a inu jayar

sarimsuү kejü jegübesü albin

nidün-dür üjegdebesü dotur-a

ülü oroyu: sarva dar-a

tay-a sarva

[3v] dokadana so hā:: egüni

geregei köbegün ügei bolbasu

šara-ber gerlejü arban jüg-tü

dalalju: jegübesü maši elbeg

ür-e nere-tü boluyu:: om

mandal-a maq-a mandal-a

so hā::

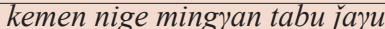

umšiǰu adislaju altan ba

jes-tür dulduyidču jegübesü

ünen mör-i olqu boluyu::

om sarva dokadan-a

sarva čodana čibada so hā:

ene juu tarni-yi jegübesü

tümen jüil maүu yaru-a arilqu

öljei qutuү maši nemekü

boluyu::

om bačir sam- $a$

maq-a bandi

[4r] so hā:: egüni qabudar

küjügün \{-dür\} qabudar yarabasu egüni

jegübesü uquүata arilqu boluyu::

om mani suundi:

dha bhasuunda-di so hā:: mal-un

qan-dur jegübesü tere mal-dur

bulayan qulqai ba gajig ramšig

arayatan ügei bolqu boluyu:

om sori sori-a maq-a vasuu-tun

so so hä::

er-e em-e qoyar/

-un sedkil ese nairabasu egüni dotur-a

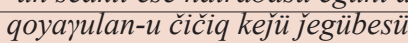

maši amurliqu bolai:: om sarva

sadurung banciy maq-a

bajar-a so hā:: nasuda

uxun ülü törün öken törül

[4v] -besü egüni jegübesü uxun

köbegün-i olqu bolai: om

čuru čuru

so hā :: er-e
THE NEW RESEARCH OF TUVA 


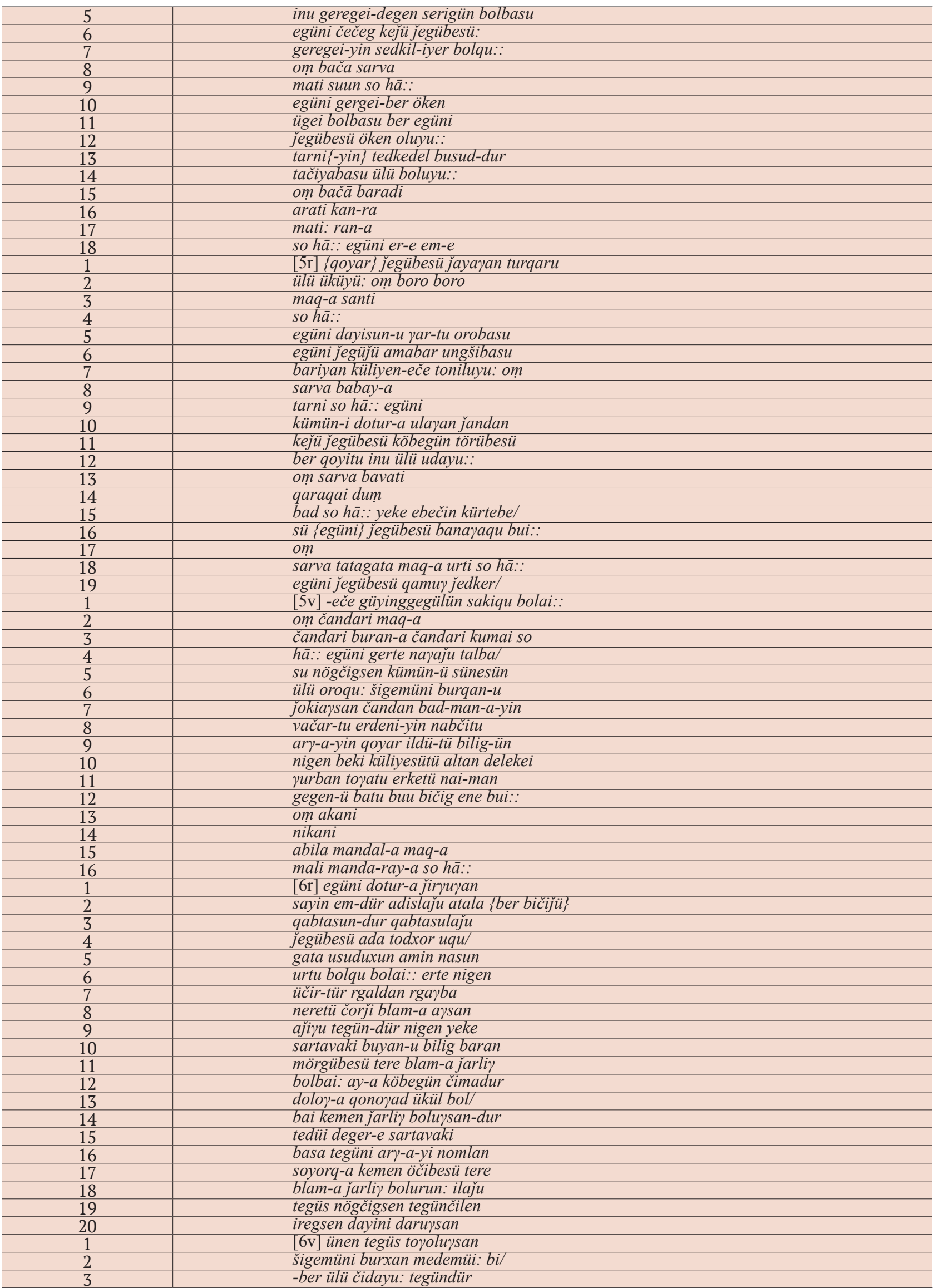




\section{НОВЫЕ ИССЛЕДОВАНИЯ ТУВЫ}

www.nit.tuva.asia
No3

oda kemen nomlabai:: tendeče

tere sartavaki ilaju tegüs

nögčigsen burxan ali jü̈g bügel

sü tere jug yayaran kürc̈ü

ilaju tegüs nögčigsen burxan-a

mörgüjü sögüdün jalbarin

öcibesü raiqamšì degedü

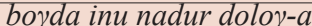

qonoyad ükül bolbai: tegün/

-ece yarqui ubadis-i nomlan

soyorq-a kemen öcibesü

ilaju tegüs nögčigsen burqan

ene buu tarni-yi bičijü

öngge-tü yar-iyan sungayiju

soyorq-a-bai:: tere sartavaki

amitan tegüni nomlan jegügsen- $\ddot{u}$

[7r] küjün-iyer doloyan sara

kürtele ese ükübei: tegüni

qoyin-a ene nom-i büri-iyer

jalaju abču ungšiju bišill

qaysan-u kücün-iyer doloyan jayun

nasulaju tegünü qoyin-a

üküged degedü qutuү-tur kürbei:

kerbe süsügten ungšibasu

uribasu tere metü öčügüken

nasun $\{\ddot{u} l u ̈\}$ abuyu: urtu nasutu

boluүad ükügsen-ü qoyin-a

burqan-u qutuy-i olqu boluyu:

\{tabun uqayan-i tegüskü boluyu\}

erigsen sedkigsen üiles öber/

-iyen bütüyü: qamuү eliy-e

čidkür qoor-a kürgen ülü

čidayu: buruүu üjelten maүu

sedkin ülü cidayu: buyan kišig

ürgülji maši nemeyü qamuү

qoor-a ada todqor bügüde

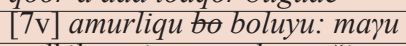

sedkil-ten-i qooros-ber rašiyan

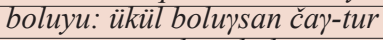

amitan ünen degedü burqan

bayši öber-ün yar-iyar

tamyalaju tangarizlaysan naiman

gegen neretü ju juи tarni

tegüsbei:: om ma ni bad

mi hum: qamuү amitan

ünen nom-un jiryal-ača ülü

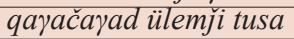

sedkigsen-ü yosuүar bütüküi/

-yin öljei qutuy orošiqu

boltuүai:: tngri-yin jiryalang/

i tegši olqu bolturai::

sayin buyan arbiduy-a: sarva

mām ghā lām::

om $\bar{a} r \bar{a}$ ba $\bar{j} \bar{a}$ nā di

bajar bani hum bad so hā::

[8r] tadyata om analai

analai bisame bisame

bhayire bhayire:

suyime suyime

sa da nadi sa da ha nadi

da na nadi da nadi

bišade bišade beyire

beyirede beyire beyirde

di bajar dhä re

bandha bandha ni bajar

ba ni yi bad: om

hum hum durum

grum grum bad

so hāa: hum durum

bandha bad namayi sakiturai

so hä:

om bajar ba ṇi bandha

\section{THE NEW RESEARCH OF TUVA}




\begin{tabular}{|c|c|}
\hline 18 & bandha bajar ba ša na ma ma \\
\hline 19 & sarva dokadan-am ba na ya \\
\hline 20 & gam hum hum bad bad \\
\hline 21 & so $h \bar{a}::::$ \\
\hline 1 & [8v] qariyal ül $\ddot{u}$ \\
\hline 2 & kürükü buu ene bui \\
\hline 3 & 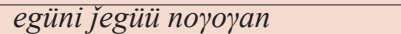 \\
\hline 4 & önggetei \\
\hline 5 & noyon qayan \\
\hline 6 & inaq qayiratai \\
\hline 7 & bolxu buu ene bui \\
\hline 8 & šara \\
\hline 9 & qali $[=a] \gamma u n$ qaniyadun \\
\hline 10 & ularan \\
\hline 11 & ha la ma la la rla \\
\hline 12 & yajar-un \\
\hline 13 & eјеed-ün buи \\
\hline 14 & om asida analn-a rga \\
\hline 15 & brabha ni sbod de bga satn-a \\
\hline 16 & da badra om juyula \\
\hline 17 & 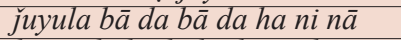 \\
\hline 18 & ha ni da hi da hi da ra da ra \\
\hline 19 & badara badara jajinta jajinta \\
\hline 20 & bhinta bhinta huṃ \\
\hline 21 & bad so hā:: hum \\
\hline
\end{tabular}

\section{Описания некоторых талисманов}

Приведем описание некоторых талисманов буу согласно тексту рукописи:

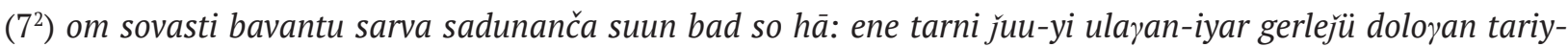
a/-u köröngge keju arban jü̈g-tü dalalbasu bayan sayin boluyu 'Ом свасти бхаванту сарва саду нанца суун пад сууха. Если этот талисман-тарни обернуть (букв. обрамить) красным, поместив внутрь (букв. сделав) семена семи злаков, и помахать им в десяти направлениях, то станешь богатым и благополучным' (НM РТ, М-828, л. 2v: 5-9) (см. puc. 1);

(10) sarim maq-a so hā:: genüte ebečin kürtebesü ene tarni buu-yi ̌̌egüjü kükü-ber beyeben utubasu ebečin arilqu bolai 'Сарим маха сууха. Если настигнет внезапная болезнь, носи на шее этот талисман-тарни, окури тело на уровне груди(?), тогда болезнь уйдет' (НМ РТ, М-828, л. 3r: 2-6);

(11) om ags-a daru hum bad so hā:: busud-luү-a yaraqu temečen uunabasu ene tarni buu-yi jigürtü uuli-yi arisun-dur kejü ebüdüg-dür

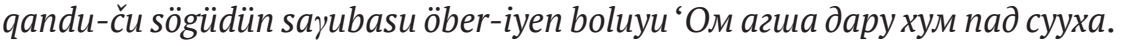
Если состязаешься с другими, покрой этот талисман-тарни кожей крылатой совы, сядь, обратив [его] к колену, тогда все исполнится само собой' (НМ РТ, М-828, л. 3r: 7-13);

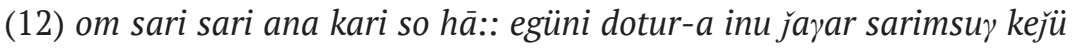
jegübesü albin nidün-dür üjegdebesü dotur-a ülü огоуи 'Ом сари сари ана кари сууха. Если внутрь положить индийский чеснок и повесить на шею, даже если увидишь албина, внутрь он не войдет' (НM РТ, М-828, л. 3r: 13-18);

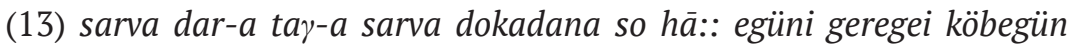
ügei bolbasu šara-ber gerlejü arban jü̈g-tü dalalju: jegübesü maši elbeg ür-e nere-tü boluуu 'Сарва дара тага сарва докадана сууха. Если у жены нет сыновей, оберни (букв. обрами) [талисман] желтым, помаши им в

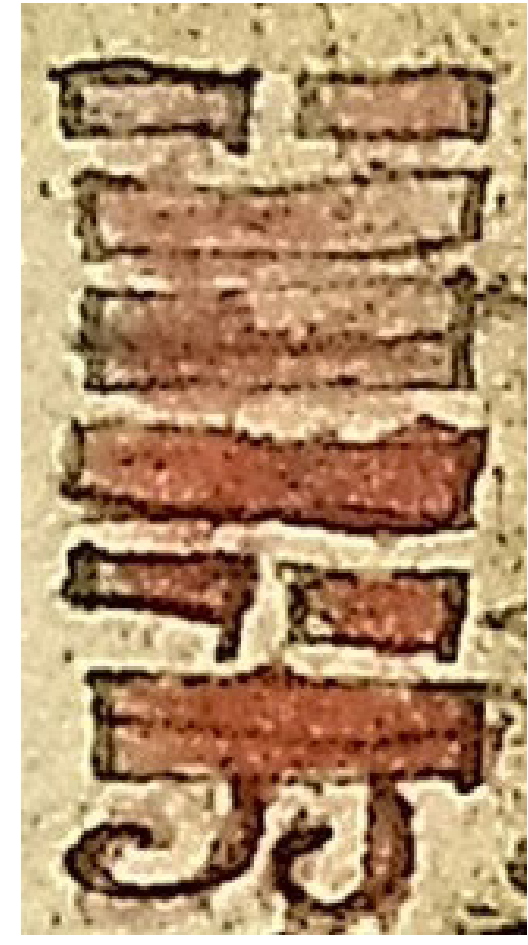

Рис. 1. Талисман № 7 для обретения богатства.

Fig. 1. Talisman 7, to get rich.

${ }^{1}$ На тибетском языке.

${ }^{2}$ Нумерация в скобках относится к нумерации изображений согласно очередности упоминания в тексте. 


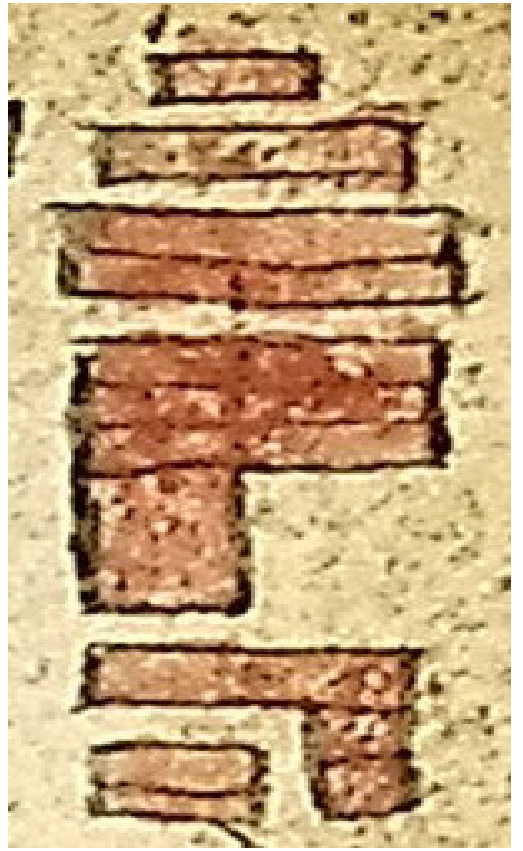

Рис. 2. Талисман № 13 для рождения сыновей. Fig. 2. Talisman 13, for sons to be born.

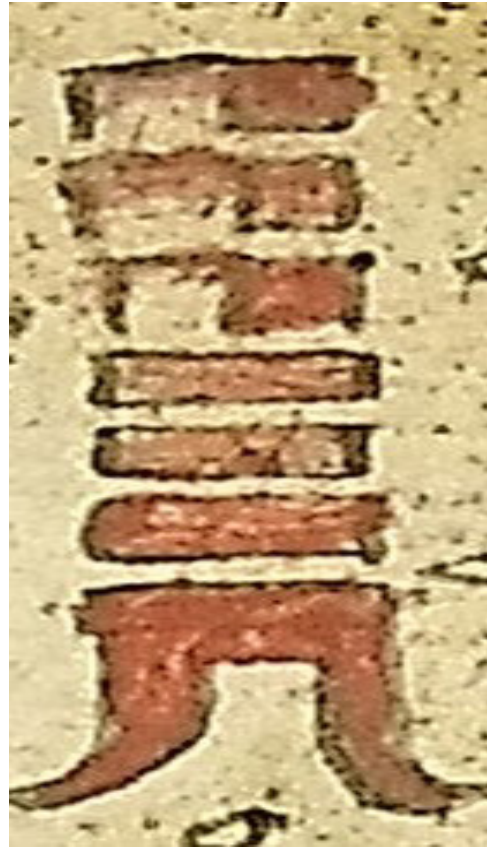

Рис. 3. Талисман № 14 для обретения истинного пути. Fig. 3. Talisman 14 to step on the true path.

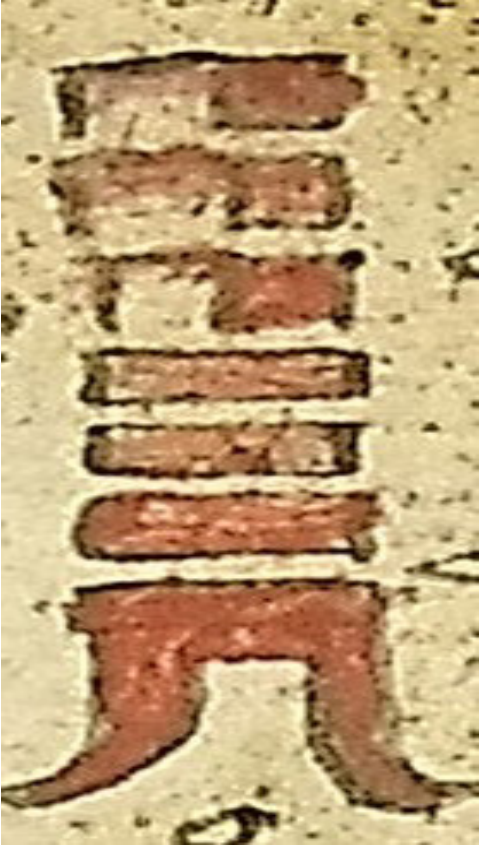

Рис. 4. Талисман № 15 для устранения препятствий. Fig. 4. Talisman 15 to avert obstacles.

десяти направлениях и носи на шее, тогда будет много сыновей’ (HM PT, M-828, л. 3r: 19-3v: 1-5) (см. puc. 2);

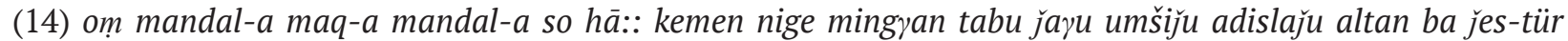
dulduyidču jegübesü ünen mör-i olqu boluyu 'Ом мандала маха мандала сууха. Если начитать еe 1500 раз и благословить, затем поместить в оправу (букв. иметь опорой) из золота или меди и носить [такой талисман] на шее, можно найти истинный путь' (НM PT, M-828, л. 3v: 5-11) (см. puc. 3);

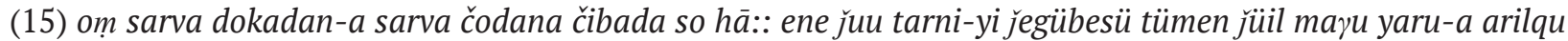
ölǰei qutuү maši nemekü boluуu 'Ом сарва докадана сарва чодана чибада сууха. Если носить на шее этот талисман-тарни, могут очиститься многочисленные плохие предзнаменования и преумножится благоденствие' (НМ РТ, М-828, л. 3v: 12-16) (см. рис. 4);

(16) om bačir sam-a maq-a bandi so hā:: egüni qabudar küjügün\{-dür\} qabudar yarabasu egüni jegübesü uquyata arilqu boluyu 'Ом бачup сама маха банди сууха. Если на шее появится нарыв, носи [этот талисман], тогда он полностью исчезнет’ (НМ РТ, М-828, л. 3v: 18-л. 4r: 3);

(17) om mani suundi: dha bhasuunda-di so hā:: mal-un qan-dur ǰegübesü tere mal-dur bulayan qulqai ba gaj̆ig yamšig arayatan ügei bolqu boluyu 'Ом мани суунди дха бхасуундади сууха. Если повесить [этот талисман] на хана домашнего скота, то не будет скотокрадства, бедствий у скотины и [нападений] хищников’ (НМ РТ, М-828, л. 4r: 4-8);

(18) om sori sori-a maq-a vasuu-tun so so hā:: er-e em-e qoyar-un sedkil ese nairabasu egüni dotur-a

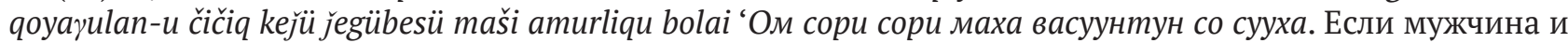
женщина не могут жить в согласии, внутрь этого [талисмана] помести [два] цветка, [символизирующих] пару, и носи на шее, тогда [жизнь] станет очень спокойной’ (НM PТ, М-828, л. 4r: 9-14);

(19) om sarva sadurung bančiy maq-a baǰar-a so hā:: nasuda uxun ülü törün öken törübesü egüni jegübesü uxun köbegün-i olqu bolai 'Ом сарва садурунг банчи маха ваджра сууха. Если рождаются не сыновья, а только дочери, носи на шее этот [талисман], тогда обретешь сына' (НM PT, M-828, л. 4r: 14-л. 4v: 2) (см. рис. 5);

(20) om čuru čuru so hā:: er-e inu geregei-degen serigün bolbasu egüni čečeg kejü jegübesü: geregei-yin sedkil-

${ }^{1}$ В фигурные скобки помещены слова или графемы, вписанные между строк. 
iyer bolqu 'Ом чуру чуру сууха. Если мужчина охладел к жене, помести внутрь него цветок и носи на шее, тогда чувства к жене вернутся’ (НМ РТ, M-828, л. 4v: 2-7);

(21) oṃ bača sarva mati suun so hā:: egüni gergei-ber öken ügei bolbasu ber egüni jegübesü öken oluуи 'Ом бача сарва мати суун сууха. Если жена не рожает девочек, носи на шее этот [талисман], тогда получишь дочь’ (НМ РT, М-828, л. 4v: 8-12);

(22) om bačà baradi aradi kan-ra mati: ran-a so hā:: egüni er-e em-e\{qoyar\}

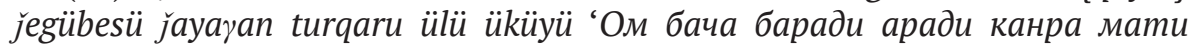
рана сууха. Если супруги будут носить на шее этот [талисман], то их не настигнет безвременная смерть’ (НМ РТ, М-828, л. 4v: 15-Л. 5r: 2);

(23) om boro boro maq-a santi so hā:: egüni dayisun-u yar-tu orubasu egüni jegüjü amabar ungšibasu bariyan küliyen-eče toniluyu 'Ом боро боро маха шанти сууха. Если попадешь в руки врагов, носи этот [талисман] и читай [дхарани] вслух, тогда избавишься от угрозы быть схваченным' (HМ PT, М-828, л. 5r: 2-7);

(24) sarva babay-a tarni so hā:: egüni kümün-i (?) dotur-a ulayan jandan kejü jеgübesü köbegün törübesü ber qоуitu inu ülü иdaуu 'Сарва бабайя тарни сууха. Если поместить внутрь красный сандал и носить на шее, то в скором времени родится сын' (НМ РТ, М-828, л. 5r: 8-12);

(25) om sarva bavati qaraqai dum bad so hā:: yeke ebečin kürtebesü \{egüni\} jеgübesü bапаүаqu buі 'Ом сарва бавати харахай дум пад сууха. Если

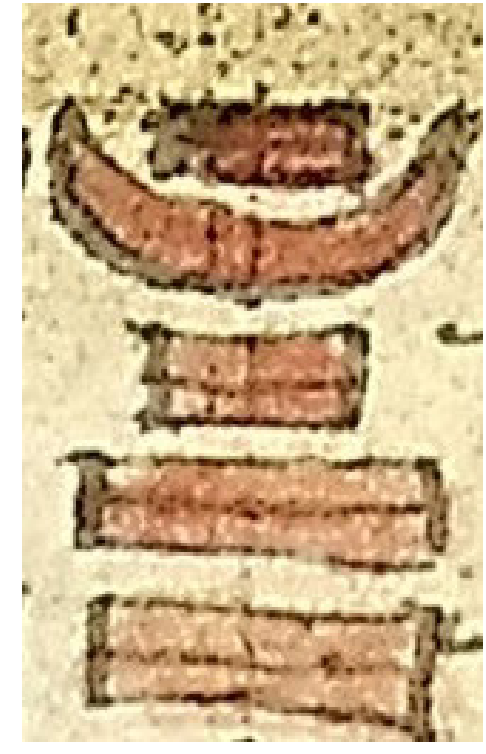

Рис. 5. Талисман № 19 для рождения сына, если рождаются только дочери. Fig. 5. Talisman 19, for sons to be born in case when only girls are born to the family. настигнет серьезная болезнь, носи его на шее и тогда излечишься’ (НM PТ, М-828, л. 5r: 13-16);

(26) om sarva tatagata maq-a urti so hā:: egüni ǰegübesü qamuү jedker-eče güyinggegülün sakiqu bolai 'Oм сарва татхагата маха урти сууха. Если будешь носить его на шее, он защитит от всех препятствий’ (НМ PT, M-828, л. 5r: 17- л. 5v: 1);

(27) om čandari maq-a čandari buran-a čandari kumai so hā:: egüni gerte najaju talbasu nögčigsen kümün-ü sünesün ülü oroqu 'Ом чандари маха чандари пурана чандари кумай сууха. Если прикрепить его [на стене] дома, душа покойника не попадет внутрь’ (НM РТ, М-828, л. 5v: 2-6).

\section{Нарратив, повествующий о создании талисмана-тарни}

После перечисления талисманов с л. 6r рукописи начинается небольшой нарратив, в котором повествуется об истории создания Буддой Шакьямуни талисмана-тарни «Восьми светоносных». По тематике он напоминает рассказы о пользе «Алмазной сутры», популярные в монгольской письменной традиции. Приведем этот фрагмент текста полностью в транслитерации и переводе на русский язык:

\begin{tabular}{|c|c|}
\hline erte nigen & Давным-давно жил один \\
\hline üčir-tür rgaldan rgayba & цорджиㄴ-лама по имени \\
\hline neretü čorji blam-a aүsan & Галдан Гагба². \\
\hline ajiخu tegün-dür nigen yeke & Когда один великий купец \\
\hline sartavaki buyan-u belig baran & поднес ему в качестве подношения \\
\hline 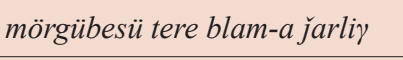 & свое имущество, лама изрек: \\
\hline bolbai: ay-a köbegün čimadur & «О юноша, спустя семь дней \\
\hline 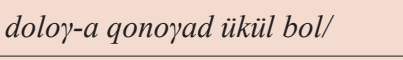 & ты умрешь». \\
\hline 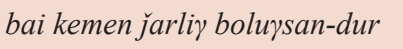 & Когда он сказал так, тотчас же \\
\hline
\end{tabular}

${ }^{1}$ Цорджи ‘наместник буддийского монастыря’, от тиб. chos rje букв. 'владыка Дхармы’.

${ }^{2}$ Имя, очевидно, является искаженным заимствованием из тибетского языка. 


\section{НОВЫЕ ИССЛЕДОВАНИЯ ТУВЫ}

\section{www.nit.tuva.asia}

№3

\section{1}

Novye issledovaniia Tuvy

\begin{tabular}{|c|c|}
\hline tedüi deger-e sartavaki & купец обратился к нему с просьбой: \\
\hline basa tegüni ary-a-yi nomlan & «Соизволь объяснить способ, \\
\hline soyorq-a kemen öčibesü tere & [как защититься от этого]». \\
\hline 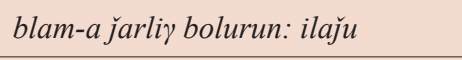 & Тогда тот лама сказал: \\
\hline tegüs nögčigsen tegünčilen & «Его знает [лишь] Бхагаван, \\
\hline iregsen dayini daruүsan & Татхагата, архат, \\
\hline 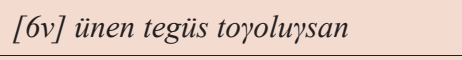 & истинно Пробужденный, \\
\hline šigemüni burxan medemüi: bil & Будда Шакьямуни. \\
\hline -ber ülü čidayu: tegündür & Я не смогу это сделать. Отправляйся \\
\hline oda kemen nomlabai:: tendeče & к нему». Тогда \\
\hline tere sartavaki ilaju tegüs & тот купец в спешке отправился \\
\hline nögčigsen burxan ali jüg bügel & туда, где находился Будда-Бхагаван, \\
\hline 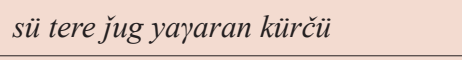 & и достиг того места, \\
\hline ilaju tegüs nögčigsen burxan-a & поклонился Будде-Бхагавану и, \\
\hline mörgüjü sögüdün jalbarin & преклонив колени, взмолился \\
\hline öčibesü raiqamši degedü & с такими словами: «Удивительный \\
\hline 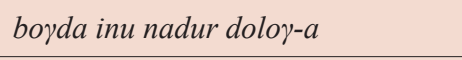 & высший владыка, спустя семь дней \\
\hline 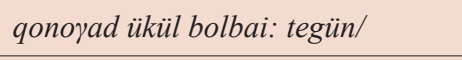 & я умру. Прошу, даруй наставление, \\
\hline -eče yarqui ubadis-i nomlan & которое защитит от этого». \\
\hline soyorq-a kemen öčibesü & Когда он обратился так, \\
\hline ilaju tegüs nögčigsen burqan & Будда-Бхагаван \\
\hline ene buu tarni-yi bičijü & записал этот талисман-тарни, \\
\hline öngge-tü (?) yar-iyan sungayiju & протянул руку и отдал его. \\
\hline soyorq-a-bai:: tere sartavaki & В силу того, что купцу было \\
\hline amitan tegüni nomlan jegügsen-ü & даровано учение и он носил \\
\hline [7r] küjün-iyer doloyan sara & на шее такой талисман, в течение \\
\hline kürtele ese ükübei: tegüni & семи месяцев он не умер. После этого \\
\hline qoyin-a ene nom-i büri-iyer & он принял ${ }^{1}$ это учение полностью, \\
\hline jalaju abču ungšiǰu bišill & читал, размышлял о нем, \\
\hline 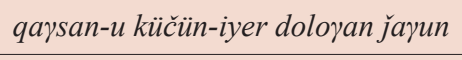 & в силу чего он прожил семьсот лет, \\
\hline nasulaju tegünü qoyin- $a$ & а после смерти \\
\hline $\begin{array}{l}\text { üküged degedü qutuү-tur kürbei: } \\
\text { (M-828, л. 6r: 6- л. 7r: 7) }\end{array}$ & достиг высшей святости. \\
\hline
\end{tabular}

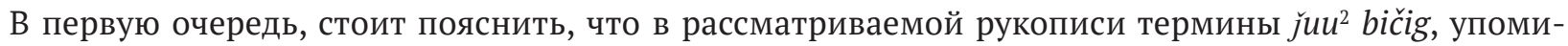
наемый в названии и начале текста, и buu tarni являются синонимичными. Талисманы buи упоминаются Ч. Боудэном в числе магических средств, направленных как на лечение болезней, так и на устранение других неблагоприятных ситуаций (Bawden, 1962: 161). Этнограф XIX в. И. А. Житецкий

\footnotetext{
${ }^{1}$ Букв. ‘пригласил’.

${ }^{2}$ Встречаются также варианты написания јu / ru.
} 
указывал следующие виды бу, бытовавшие у калмыков: от болезни, от испуга, от грозы и пр. (Житецкий, 1893: 29).

Талисманы, которые мы встречаем в рукописи, могут предназначаться для:

- лечения болезней (НМ РТ, М-828, л. 3r: 10; л. 3v: 16; л. 5r: 25; л. 8v: 32);

- благополучия скота (НМ РТ, М-828, л. 4r: 4-8);

- защиты от покойников (НМ РТ, М-828, л. 5v: 2-6);

- исправления различных семейных ситуаций, связанных с деторождением (НM PT, M-828, л. 2v: 10-14; л. 3r: 18-3v: 5; л. 4r: 14-4v: 2 ; л. 4v: 8-12; л. 5r: 7-12) и взаимоотношениями между супругами (НМ РТ, М-828, л. 2v: 15-3r: 2; л. 4r: 9-14; л. 4v: 2-7);

- достижения общих целей - благоденствия (НM РТ, М-828, л. 2v: 5-9; л. 3v: 12-16), исполнения задуманного (НМ РТ, М-828, л. 3r: 7-13);

- достижения высшей цели буддийского пути (НМ РТ, М-828, л. 3v: 5-11).

Дхарани из «Сутры о восьми светоносных неба и земли» om akani nikani abila mandal-a maq-a mali manda-ray-a so hä используется для талисмана, который нужно носить на шее, поместив внутрь шесть снадобий и завернув в бумагу, благодаря чему будет полностью устранено воздействие вредоносных

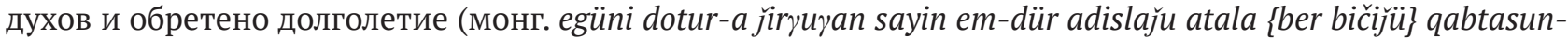
dur qabtasulaju jegübesü ada todxor uqugata usuduxun amin nasun urtu bolqu bolai) (HM PT, M-828, л. 6r: 1-6).

Из предметов, которые помещаются внутрь, упоминаются семена семи злаков (НМ РТ, М-828, л. 2v: 7), цветок (HМ PT, M-828, л. 4r: 13; л. 4v: 6), чеснок (HM PT, M-828, л. 3r: 16), снадобья (НM PT, M-828, л. 6r: 2). В качестве основы (обрамления) талисмана могут быть использованы красная (НM РТ, М-828, л. 2v: 7) или желтая ткань (НM РТ, М-828, л. 3v: 3), кожа совы (НM РТ, М-828, л. 3r: 10-11), золото или медь (НМ PT, M-828, л. 3v: 9-10).

Интересна данная рукопись и тем, что в конце содержится нарратив о пользе этого сочинения как талисмана, дарованного самим Буддой некоему купцу. Стоит упомянуть, что существует аналогичный подобным сборникам о пользе «Алмазной сутры» нарратив о пользе «Сутры о восьми светоносных неба и земли», состоящий из восьми рассказов (Мирзаева, 2020а). Использование в этом фрагменте тибетских заимствований (rgaldan rgarba, čorji blam-a) позволяет предположить, что текст был переведен с тибетского языка.

\section{Заключение}

Рассматриваемая рукопись «Naiman gegen neretü juи tarni» содержит уникальные материалы по традиции бытования талисманов буу в традиции тибето-монгольского буддизма. Обнаружение другой версии этого сочинения в рукописной коллекции Харбухын Балгас, датируемой началом XVII вв., позволяет предположить, что оно (возможно, как переводной памятник) получило распространение в период доклассического монгольского языка, предшествовавший оформлению монголоязычного буддийского канона.

Для описания своеобразия тувинской традиции требуется дальнейшая работа по изучению аналогичных книжных талисманов и самих изображений в фондохранилищах монгольских рукописей. Отдельную ценность, по нашему мнению, представляют содержащиеся в рукописи сведения об изображениях и сакральных формулах, которые вкладываются в тот или иной талисман, материалу, из которого он должен быть изготовлен, и помещаемым внутрь предметам, что также требует дальнейшего, более подробного изучения.

Одним из главных вопросов, обусловленных названием рукописи, является ее связь с кругом версий «Сутры о восьми светоносных неба и земли». Как указывалось в предыдущих публикациях автора, в тибето-монгольской традиции эта дхарани-сутра представлена двумя различными по содержанию версиями, вошедшими в Ганджур и сборник ритуальных текстов «Сундуй» (Мирзаева, Тувшинтугс, 2019; Мирзаева, 2019b). В. Хайссиг пишет о третьей версии сутры из коллекции Олон-сюмэ «Qutuү-tu qas erdeni. naiman gegen neretü sudur» ('Святая сутра восьми светоносных, нефритовая драгоценность') (Heissig, 1976: 319). Компонент qas erdeni ‘нефритовая драгоценность' в названии рукописи, на наш взгляд, может коррелировать с названием одного из наиболее известных в монгольской письменной традиции гадательных сочинений «Нефритовая шкатулка» (монг. qas qaүurča $)$ ). Содержащееся в книге А. М. Позднеева «Очерки быта буддийских монастырей» описание буддийских ритуалов засал (букв. 
‘исправление’), в процессе которых зачитывается «Сутра о восьми светоносных неба и земли» («Найман гэгээн») (Позднеев, 1993: 414-433), позволяет сделать вывод, что она была связана с астрологическими и гадательными практиками. Это, в свою очередь, может служить объяснением, почему рассмотренная в данной статье рукопись получила такое название.

\section{Благодарности}

Автор выражает глубокую благодарность профессору, доктору филологических наук, директору Национального музея им. Алдан-Маадыр Республики Тыва К. А. Бичелдею за ценные замечания, высказанные при ознакомлении с рукописью статьи.

\section{СПИСОК ЛИТЕРАТУРЫ}

Житецкий, И. А. (1893) Очерки быта Астраханских калмыков. Этнографические наблюдения 1884-1886 гг. М. : Тип. М. Г. Волчанинова. 70 с.

Мирзаева, С. В. (2019а) Монгольская рукопись «Сутры о восьми светоносных» (монг. Найман гэгээн) из тувинского архива // Новые исследования Тувы. № 3. С. 198-207. DOI: https://www.doi.org/10.25178/nit.2019.3.16

Мирзаева, С. В. (2019b) Монгольский перевод «Сутры о восьми светоносных» как образец дхарани-сутр // Новый филологический вестник. № 4 (51). С. 409-425. DOI: https://www.doi.org/10.24411.2072-9316-2019-00117

Мирзаева, С. В. (2020а) Монгольский комментарий к «Сутре о восьми светоносных»: об особенностях жанра // Новый филологический вестник. № 2 (53). С. 280-296. DOI: https://www.doi.org/10.24411/2072-9316-2020-00049

Мирзаева, С. В. (2020b) О двух монгольских переводах «Сутры о восьми светоносных неба и земли» // Новый филологический вестник. № 4 (55). С. 371-387. DOI: https://www.doi.org/10.24411/2072-9316-2020-00117

Мирзаева, С. В., Тувшинтугс, Б. (2019) Монголоязычные версии «Сутры о восьми светоносных» (монг. Найман гэгээн, калм. Нәәмн гегән): об истории изучения и списках в фондохранилищах России // Oriental Studies. № 4. C. 716-727. DOI: https://www.doi.org/10.22162/2619-0990-2019-44-4-716-727

Мирзаева, С. В., Тувшинтугс, Б. (2020) Модель буддийской космологии в «Сутре о восьми светоносных» // Монголоведение. № 2. С. 271-287. DOI: https://www.doi.org/10.22162/2500-1523-2020-2-271-287

Позднеев, А. М. (1993) Очерки быта буддийских монастырей и буддийского духовенства в Монголии в связи с отношением сего последнего к народу. Репринтное изд. Элиста : Калм. кн. изд-во. 512 с.

Срба, О. (2017) «Огторгуй газрын найман гэгээн» судрын асуудалд: «Харш засах найман гэгээн» судрын нэгэн шинэ хувилбар [К вопросу о сутре «Восемь светоносных неба и земли»: новый список сутры «Восьми светоносных, устраняющих неблагоприятствование»] // The Mongolian Kanjur. International Studies / ed.-in-chief S. Chuluun. Ulaanbaatar : Institute of History and Archaeology. 354 х. Х. 224-246. (На монг. яз.).

Шараева, Т. И. (2009) Обереги в детском цикле у калмыков // Известия Алтайского государственного университета. № 4/3 (64/3). С. 259-262.

Bawden, Ch. (1962) The supernatural element in sickness and death according to Mongol tradition. Part II // Asia Major. Vol. 9. Pp. 153-178.

Benebell, W. (2016) Tao of Craft: Fu Talismans and Casting Sigils in the Eastern Esoteric Tradition. Berkley : North Atlantic Books. 616 p.

Chiodo, E. (2009) The Mongolian Manuscripts on Birch Bark from Xarbuxyn Balgas in the Collection of the Mongolian Academy of Sciences. Part 2. Wiesbaden : Harrassowitz Verlag. 338 p.

Heissig, W. (1976) Die Mongolischen Handschriften-Reste aus Olon-süme Innere Mongolei (16.-17. Jahrhundert). Wiesbaden : Harrassowitz Verlag. $633 \mathrm{~s}$.

Sazykin, A. G. (1994) Catalogue of the Mongol manuscripts and xylographs preserved in the Library of the Tuvan Ethnological Museum “Sixty Heroes” (Kyzyl) // Acta Orientalia Academiae Scientarum Hung. Tomus XLVII (3). P. $327-407$.

Tsendina, A. D. (2020) 'Booklore’ Talismans in Daily Life of the Mongols: A Case Study of Two Collections of Mongolian Manuscripts // Oriental Studies. Vol. 13(6). P. 1632-1640. DOI: https://www.doi.org/10.22162/2619-0990-2020-52-6$1632-1640$

Дата поступления: 12.07.2021 2.

\section{REFERENCES}

Zhitetsky, I. A. (1893) Ocherki byta Astrahanskih kalmykov. Etnograficheskie nablyudeniya 1884-1886 gg. [Astrakhan Kalmyks: Sketches of Everyday Life. Ethnographic Observations, 1884-1886]. Moscow, M. G. Volchaninov. 70 p. (In Russ.). 
Mirzaeva, S. V. (2019a) Mongol'skaya rukopis' «Sutry o vos'mi svetonosnyh» (mong. Najman gegeen) iz tuvinskogo arhiva [A Mongolian manuscript of 'The Sutra on the Eight luminous of heaven and earth' (mong. Naiman gegen) from the Tuvan archive]. New Research of Tuva, no. 3, pp. 198-207. (In Russ.). DOI: https://www.doi.org/DOI: 10.25178/nit.2019.3.16

Mirzaeva, S. V. (2019b) Mongol'skij perevod «Sutry o vos'mi svetonosnyh» kak obrazec dharani-sutr [A Mongolian Translation of the "Sutra of Eight Luminous" as Dhāranī-sūtra]. New Philological Bulletin, no. 4 (51), pp. 409-425. (In Russ.). DOI: https://www.doi.org/10.24411.2072-9316-2019-00117

Mirzaeva, S. V. (2020a) Mongol'skij kommentarij k «Sutre o vos'mi svetonosnyh»: ob osobennostyah zhanra [A Mongolian Commentary on the "Sutra of Eight Luminous": Features of the Genre]. The New Philological Bulletin, no. 2 (53), pp. 280-296. (In Russ.). DOI: https://www.doi.org/10.24411/2072-9316-2020-00049

Mirzaeva, S. V. (2020b) O dvuh mongol'skih perevodah «Sutry o vos'mi svetonosnyh neba i zemli» [Two Mongolian Translations of the "Sūtra of Eight Luminous of Heaven and Earth" Revisited]. The New Philological Bulletin, no. 4 (55), pp. 371-387. (In Russ.). DOI: https://www.doi.org/10.24411/2072-9316-2020-00117

Mirzaeva, S. V. and Tuvshintugs B. (2019) Mongoloyazychnye versii «Sutry o vos'mi svetonosnyh» (mong. Najman gegeen, kalm. Nəəmn gegən): ob istorii izucheniya i spiskakh $\mathrm{v}$ fondohranilishchakh Rossii [Mongolian-Language Versions of The Sutra of the Eight Luminous (Mong. Найман гэгээн, Kalm. Нәәмн гегән): a History of studies and copies in Russian repositories]. Oriental Studies, no. 12(4), pp. 716-727. (In Russ.). DOI: https://www.doi.org/10.22162/2619-09902019-44-4-716-727

Mirzaeva, S. V. and Tuvshintugs B. (2020) Model' buddiiskoi kosmologii v «Sutre o vos'mi svetonosnykh neba i zemli» [The Sūtra of Eight Luminous of Heaven and Earth: a Buddhist cosmological model revisited]. Mongolian Studies, no. 12 (2), pp. 271-287. (In Russ.). DOI: https://www.doi.org/10.22162/2500-1523-2020-2-271-287

Pozdneev, A. M. (1993). Ocherki byta buddiiskikh monastyrei i buddiiskogo duhovenstva $v$ Mongolii v svyazi s otnosheniem sego poslednego $k$ narodu [Sketches of the life of Buddhist monasteries and clergy in Mongolia, in connection with the latter's relation to the people]. Reprint ed. Elista, Kalm. Book Publ. 512 p. (In Russ.).

Srba, O. (2017) «Ogtorguj gazryn najman gegeen» sudryn asuudald: «Harsh zasah najman gegeen» sudryn nehgehn shineh huvilbar [On the Problem of the Sutra «Eight Lights of Heaven and Earth»: A new variant of Sutra of «Eight Lights Averting Unfavourable»]. In: The Mongolian Kanjur. International Studies / ed.-in-chief S. Chuluun. Ulaanbaatar, Institute of History and Archaeology. 354 p. Pp. 224-246. (In Mong.).

Sharaeva, T. I. (2009) Oberegi v detskom tsikle u kalmykov [Amulets in the child's rituals among Kalmyks]. Izvestiya Altaiskogo gosudarstvennogo universiteta, no. 4/3 (64/3), pp. 259-262. (In Russ.).

Bawden, Ch. (1962) The Supernatural Element in Sickness and Death According to Mongol Tradition. Part II. Asia Major, vol. 9, pp. 153-178.

Benebell, W. (2016) Tao of Craft: Fu Talismans and Casting Sigils in the Eastern Esoteric Tradition. Berkley, North Atlantic Books. 616 p.

Chiodo, E. (2009) The Mongolian Manuscripts on Birch Bark from Xarbuxyn Balgas in the Collection of the Mongolian Academy of Sciences. Part 2. Wiesbaden, Harrassowitz Verlag. 338 p.

Heissig, W. (1976) Die Mongolischen Handschriften-Reste aus Olon-süme Innere Mongolei (16.-17. Jahrhundert). Wiesbaden, Harrassowitz Verlag. 633 s.

Sazykin, A. G. (1994) Catalogue of the Mongol manuscripts and xylographs preserved in the Library of the Tuvan Ethnological Museum “Sixty Heroes” (Kyzyl). Acta Orientalia Academiae Scientarum Hung, vol. XLVII (3), pp. $327-407$.

Tsendina, A. D. (2020) 'Booklore’ Talismans in Daily Life of the Mongols: A Case Study of Two Collections of Mongolian Manuscripts. Oriental Studies, vol. 13(6), pp. 1632-1640. DOI: https:/www.doi.org/10.22162/2619-0990-2020-52-6-16321640

Submission date: 12.07.2021. 